\title{
Más allá de las migraciones internas. Destierro y despojo en la guerra
}

\section{Beyond internal migrations: Exile and dispossession in war}

\author{
Flor Edilma Osorio Pérez* \\ Universidad Javeriana, Bogotá, Colombia \\ orCID: https://orcid.org/oooo-oooI-7844-403X \\ ISSN: ISSN-OI85-4259; e- ISSN: 2007-9176 \\ DoI: http://dx.doi.org/I0.28928/ri/762014/atci/osorioperezfe
}

\section{Resumen}

Las migraciones forzadas internas constituyen una modalidad de despojo y desterritorialización cada vez más frecuente y ampliada en América Latina. La sobreexplotación justificada en el desarrollo y el ejercicio de la violencia constituyen dos polos articulados entre los cuales oscilan y se mezclan modalidades derivadas de conflictos armados, desastres ambientales, obras de infraestructura y mega proyectos minero-energéticos. Estas dinámicas están profundamente relacionadas, como lo muestra el caso colombiano, y aunque comparten características específicas, están insertas en condiciones estructurales precarias que dificultan gravemente su resolución oportuna, hecho que impacta prolongadamente a un empobrecimiento ampliado e inercial.

Palabras clave: desplazamiento forzado, desarrollo, desterrirorialización, desastres, conflictos ambientales

\begin{abstract}
Forced internal migration is a way of theft and deterritorialization increasing in Latin America. Overexploitation, justified in the development and exercise of violence are two articulated poles which swing and mix among armed conflicts, environmental disasters, infrastructure, and mining-energetic megaprojects; dynamics deeply related, as shown in the colombian case. Those activities are embedded in such precarious structural conditions, that disable it's timely resolution, fact that generates a long-term impact on a growing and inertial impoverishment.
\end{abstract}

Key words: forced displacement, development, deterritorialization, disasters, environmental conflicts

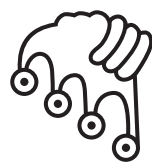

\section{IZTAPALAPA}

Agua sobre lajas

* Profesora titular de la Universidad Javeriana, Bogotá, adscrita al Departamento de Desarrollo Rural y Regional, Facultad de Estudios Ambientales y Rurales. Coordina el grupo de investigación "Conflicto, región y sociedades rurales" reconocido por Colciencias. fosorio@ javeriana.edu.co 


\section{Introducción}

escubrir, comerciar, viajar, establecerse, dominar, conquistar, progresar,
conocer, protegerse, huir, abandonar... Estas y muchas otras razones están
presentes en las motivaciones y búsquedas que dinamizan las migraciones humanas. Partir, a la vez que conlleva rupturas dolorosas, implica articulaciones y nuevos lazos, afirmaciones de lo propio y reconfiguraciones de todo orden con fuertes sincretismos. En su transcurrir se reacomodan todas las dimensiones humanas individuales y colectivas, se mantienen persistencias y se reorientan prácticas y comprensiones de la vida. La migración produce confrontación de alteridades, entre "los otros" y"nosotros", entre residentes y recién llegados, con toda la carga material y simbólica que la antigüedad supone (Elias y Scotson, 1997).

Las migraciones son procesos complejos que tocan temas de orden sociocultural, económico y político muy sensibles: la soberanía, las identidades, la ciudadanía, la pertenencia, los derechos, las libertades, los proyectos de vida, las pertenencias, las distancias y las cercanías. De allí la riqueza y posibilidad que ofrecen las migraciones y movilidades de población para comprender la naturaleza humana y sus sociabilidades en cualquier tiempo y lugar.

Muchas migraciones en el mundo no son fruto de esa "pulsión migratoria" (Maffesoli, 1997) que busca una evasión e incita al cambio de lugar y de hábitos como mecanismo de realización personal. Millones de personas deben huir, abandonar sus lugares, sufrir el destierro debido a diferentes formas de coacción y de constreñimiento, situaciones límite que producen vivencias y sentidos muy distintos para quienes migran y también para las sociedades a donde llegan. Son denominadas migraciones forzadas, categoría que se queda corta y que oculta más de lo que enuncia. Caben allí diversas experiencias, causas y dinámicas cuyo hilo transversal es el traumatismo que acompaña una salida en medio del terror y el dolor, un difícil recomenzar en otros lugares, en medio del empobrecimiento repentino y de una profunda vulnerabilidad que puede perdurar por mucho tiempo en medio de tortuosas experiencias de frustración, abandono y rechazo. 
Dado que estos procesos se suceden usualmente en contextos con problemas estructurales importantes, las posibilidades de volver a empezar y lograr alguna estabilidad integral en tiempo prudencial, son excepcionales. Las condiciones de empobrecimiento abruptas y totales, generan tal vulnerabilidad que con frecuencia se superponen en sus vidas nuevas modalidades de dominación y despojo, potenciando los impactos traumáticos y haciendo cada vez más lejanas las posibilidades de restablecimiento sostenible.

Sobre estas modalidades de destierro dentro de su mismo país, así como de las diferencias y relaciones que se tejen entre ellas, trata este texto construido desde la realidad colombiana. Inicialmente se hace una discusión en torno a las migraciones internas forzadas, en el marco de una continuidad invisibilizada y agravada. Posteriormente, se hace un recorrido por tres dinámicas de destierro interno: el desplazamiento forzado por el conflicto armado; las obras de infraestructura y los megaproyectos minero-energéticos, y los desastres ambientales. El texto cierra con unas reflexiones que contrastan estas modalidades migratorias que se dan en medio de la arbitrariedad, el temor, la urgencia y el constreñimiento.

\section{Migraciones internas, destierros, desarraigos $y$ despojos forzados}

Los estudios sobre las migraciones internas tuvieron en América Latina un auge hacia mediados del siglo xx y hasta la década del 80, pero su interés ha decaído sustancialmente. Una de las expresiones más persistentes de la migración interna es el flujo rural urbano, que tiene diferentes ritmos, temporalidades e intensidades, una vieja dinámica vigente que está en la base histórica de la configuración de las ciudades latinoamericanas, y que busca compensar los desequilibrios estructurales en la distribución de recursos y de oportunidades entre el campo y la ciudad. La migración rural-urbana en Colombia, si bien mantiene la dinámica tradicional de suplir el mercado de trabajo precario, en una clara división de género, de empleo doméstico en las mujeres (Melguizo, 2003; Posso, 2008) y trabajo de construcción para los hombres, está mostrando nuevos y perversos intereses. Se conoce como trata de personas, un lucrativo negocio interno e internacional que compite con el de drogas y el de armas en el mundo (Universidad Nacional, unOdC, 2009; Fundación Esperanza, 20II).

Además del flujo rural-urbano las migraciones internas se dan también entre zonas rurales, entre zonas urbanas, dentro de un mismo entorno urbano y también 
de la ciudad al campo, movimientos que, pese a no ser muy grandes, tienen importancia significativa en entornos locales y regionales. Tales procesos han sido recogidos en estudios sobre la colonización de la Orinoquía y la Amazonía (Molano, 1987, 1989, 1990; Uribe, 1993, Jaramillo y otros, 1989) y sobre la colonización antioqueña (Parsons, 1997).Los análisis de configuración de regiones como el Magdalena Medio (Archila y otros, 2006), Urabá (García, 1996), Putumayo (Piña, 20I2; Ramírez, 200I), Caldas (Tobasura, 2004), entre otros, muestran movimientos poblacionales importantes con motivos que cruzan el acceso a la tierra, con la necesidad de protección y de escape de situaciones de conflicto armado regional, de tensiones y amenazas que han sido una constante durante el siglo xx; el desplazamiento forzado se acentúa y alcanza diversas zonas del país con la violencia bipartidista de mediados de ese siglo, la misma que con nuevos actores y dinámicas se mantiene, en una espiral de destierro y desolación cada vez más ampliada. Se suman, además, las dinámicas derivadas de los cultivos de uso ilícito que han caracterizado las últimas tres décadas de la historia colombiana (Ferro y otros, 1999). Las migraciones internas en todas sus expresiones son un muy buen termómetro de las desigualdades regionales e históricas que van marcando injusticias y fuertes desequilibrios económicos y políticos.

Luego de siglos de abandono y menosprecio de los territorios rurales y ante la evidencia de sus límites, el gran capital impone una revaloración funcional y extractiva de estos lugares, en tanto reserva de recursos mineros y energéticos, productor a gran escala de alimentos, agrocombustibles y germoplasma, zona de turismo y recreación, entre otros usos. Desde estos intereses más recientes se impone la expulsión de la población que estorba su dinámica expansionista a través de presión, la arbitrariedad y también la fuerza.

Las grandes obras de infraestructura que se construyen bajo la promesa de atender a intereses generales, sacrificando para ello los procesos vitales de las comunidades allí asentadas, imponen profundas modificaciones en sus territorios que obligan su salida involuntaria. Explotaciones mineras y agroindustriales, represas, carreteras y otras grandes obras son justificadas usualmente como parte del costo del desarrollo con la promesa de compensaciones en términos de empleo y producción. Sin embargo, usualmente sus beneficios se orientan a sectores muy delimitados $y$, rápidamente, se convierten en nuevos resortes para fortalecer procesos de acumulación de capitales privados, en medio de un alto costo ambiental silenciado.

Los impactos de un saqueo acumulado resultante de un manejo inadecuado de los recursos naturales, emisión de gases, contaminación y desviación de fuentes de agua, tala indiscriminada, entre muchos otros, se reflejan en el fenómeno del cambio climá- 
tico. Se trata de "una espiral mundial descendente de tiempo meteorológico extremo y desastres, junto a la involución del desarrollo, el aumento de los desplazamientos y las tensiones agravadas por los recursos y la desestabilización de los estados frágiles" (ONU, 2013). Sus múltiples y graves manifestaciones a través de desastres y catástrofes no evidencian responsables. Quienes resultan más fácilmente afectadas son las poblaciones ya empobrecidas y vulnerables, que refuerzan y concentran ciclos de pobreza y miseria producidos por vías, aparentemente, diferentes.

La superposición de diversas formas de destierro, coacción y despojo en una misma experiencia vital desborda la capacidad descriptiva y explicativa de la migración, en su acepción clásica. La decisión de migrar y las condiciones en las que se decide constituyen factores claves para mostrar profundas diferencias entre la migración forzada o por coacción y la no forzada, también llamada por algunos autores como voluntaria. Sin embargo, la insistencia teórica en buscar respuesta a la pregunta de por qué migran las personas, se ha concentrado en explicaciones de orden puramente económico, situando los factores de orden sociofamiliar, cultural y político de manera marginal. El "interés excluyente por la migración voluntaria" (Arango, 2000:44) ha dejado un gran vacío en la comprensión de aquellas migraciones que tienen una clara coacción derivada de diferentes condiciones.

La migración forzada producida a raíz de las guerras, los conflictos políticos y religiosos, los problemas ambientales, las hambrunas, entre otros, ha sido objeto de debates de orden sociojurídico, que buscan definir la responsabilidad de la ayuda y protección para con las víctimas derivada de acuerdos y pactos de tipo ético-normativo del derecho internacional. ${ }^{1}$ De allí se han retomado criterios para abordar el fenómeno del desplazamiento forzado interno a través de los Principios Rectores de los Desplazamientos Internos, aprobados por la Asamblea de las Naciones Unidas en 1998. Sin embargo, es evidente que los países han construido un blindaje institucional basado en la soberanía y el principio de no intervención en asuntos internos, que impide una mayor protección a quienes sufren el destierro en su propio país. Pero además, la acción reguladora de los Estados más que prevenir, reparar y atender los daños producidos por el destierro y el despojo, busca controlar e impedir que su des-

1 Son tres las fuentes centrales: la Declaración Universal de Derechos Humanos, el Derecho Internacional Humanitario -en tanto conjunto de tratados busca atenuar los efectos de la confrontación armada, para civiles y militares- y el Derecho Internacional de los Refugiados, que se recoge en la Convención de i95 y las modificaciones del Protocolo de 1967. La Convención define la categoría de refugiado, los procesos de demanda de asilo y precisa diferentes medidas de protección para los refugiados por parte de los países firmantes, que se comprometen a solidarizarse con ciudadanos ajenos. 
plazamiento se prolongue por fuera de las fronteras nacionales evitando corrientes migratorias indeseables que disminuyen su propia legitimidad (Vidal, 2007). Estas condiciones de vulnerabilidad dentro del Estado del cual se es ciudadano, reducen aún más los mecanismos de protección y atención de desterrados y despojados, dejando las respuestas a merced de una ya desequilibrada correlación de fuerzas.

La diferenciación de las causas y condiciones que rodean la migración interna es fundamental porque de allí se derivan posibilidades de trayectorias que incluyen los procesos mismos de recomenzar sus vidas en otros lugares, no solo por las condiciones materiales que rodean y posibilitan ese proceso, sino también por la representación que la sociedad hace de los inmigrantes, que marca en buena parte las relaciones que se establecen entre residentes y recién llegados.

Hay que reconocer, sin embargo, que tal diferenciación no siempre resulta fácil, precisamente por la superposición de circunstancias y por el carácter dinámico que toma el proceso migratorio. Así, se dan experiencias claramente marcadas por la ilusión y la clara decisión de salir -lo cual no exime la nostalgia-, como la salida a estudiar de muchos jóvenes. En el otro extremo, se identifican decisiones en condiciones evidentes de coacción, orden o amenaza, como las que se dan por la guerra o por desastres ambientales. Sin embargo, hay una vasta zona gris en la que, por ejemplo, detrás de aparentes razones económicas, asimiladas a decisiones voluntarias, se esconden graves condiciones de empobrecimiento, falta de empleo, violencia intrafamiliar u otras circunstancias derivadas de la violencia estructural (Galtung, I998); vistas en esta perspectiva, son decisiones altamente condicionadas por el riesgo potencial, los impactos en el desarrollo personal y las restricciones para el ejercicio de los derechos fundamentales. Aparentes contrataciones laborales dentro y fuera del país orientadas especialmente a mujeres jóvenes, luego de un enganche laboral "voluntario", se convierten en trabajo forzado lícito e ilícito, como la prostitución y comercio sexual, que se sostiene con la violencia física y psicológica, y configura la esclavitud moderna (Bales, 2000).

La diversidad de situaciones y su carácter cambiante exigen una mirada que dé cuenta de los cruces y dinámicas del proceso migratorio, entre dos extremos: uno que se relaciona con la libertad y la autonomía y el otro con la coacción. Entre uno y otro extremo se configuran formas, expresiones e intensidades diferentes de libertad y de coerción. Esta perspectiva se acerca a la propuesta de Richmond (1993) que identifica, por una parte, una migración reactiva, que se decide en medio de restricciones severas a la libertad, de pánico individual y colectivo, de una crisis que deja pocas alternativas para escapar de amenazas intolerables. Por otra parte, sitúa una migración proactiva que se elige racionalmente buscando maximizar las 
ventajas ${ }^{2}$, La gama de fuentes de coerción y de subordinación que se conjugan en el tiempo y en el espacio, no solo frente al momento de la decisión sino al conjunto del proceso migratorio para poblaciones empobrecidas, permite una mirada más comprensiva de la migración como proceso, poniendo en el centro de la discusión el ejercicio de la autonomía personal en la decisión y en el proceso migratorio, así como de la libertad y realización individual y familiar de quienes emigran.

En tanto comportamiento humano multidimensional que conjuga lo individual y lo colectivo, con una gama de actores, experiencias, motivaciones, contextos muy diversos, el estudio de los procesos migratorios tiene muchos desafíos."La migración es difícil de definir, complicada de medir, polifacética y multiforme y se resiste a la teorización [...] es opaca al razonamiento teórico en general y a los modelos formales en particular" (Davis y Arango citados por Arango, 2000ः45). Por lo mismo, requiere ser leída y comprendida desde sus manifestaciones en su propio contexto histórico y social en el cual cobran sentido, usando las tipologías y categorías como herramientas flexibles, que se enriquecen en la crítica y el contraste con una realidad diversa y dinámica.

\section{Destierros y despojos derivados del conflicto armado}

Colombia vive un conflicto armado de larga duración, una guerra irregular que con ritmos diferentes, actores y énfasis, se ha mantenido vigente durante más de sesenta años. En ese tiempo se ha tejido una relación a la vez simbiótica y contradictoria con dinámicas democráticas formales, configurando un proceso complejo, acumulativo y persistente, que se ha desarrollado y enquistado en todas las dimensiones de la sociedad y que tiene expresiones concretas que han marcado profundamente la vida de millones de colombianos. La guerra juega de múltiples maneras y en diversas escalas cruzadas: invisibiliza situaciones claves, distorsiona las realidades, reorienta recursos y esfuerzos, justifica medidas represivas, militariza material y simbólicamente la sociedad, alimenta y exacerba muchas formas de violencia cotidiana y delincuencia

2 Entre estos dos extremos, las personas buscan respuestas para diluir la ansiedad generada por un fracaso del sistema social y para promover las necesidades del individuo, biológicas, económicas y políticas. Richmond propone una aproximación multivariada con cinco grupos de factores: los políticos, los económicos, los medioambientales, los sociales y los bio-psicológicos. El autor define veinticinco tipos de migración reactiva que combinan de manera distinta las prioridades que determinan el movimiento de la población. 
social, que pasan inadvertidas. A la sombra de la guerra y de todos sus horrores, se camuflan intereses de diverso orden, se reacomodan relaciones de poder local y regional, se usurpan capitales y se resuelven violentamente viejas rencillas cotidianas. Aunque una explicación hegemónica del conflicto armado lo reduce definiendo como gran y único enemigo a la subversión, la dinámica del conflicto armado colombiano se acerca más a la dinámica de una guerra civil marcada por "procesos complejos y ambiguos que fomentan una aparente mezcla masiva aunque variable de identidades y acciones, al punto de ser definida por esa mezcla" (Kalivas, 2004:52).

Grupos guerrilleros, grupos paramilitares, fuerzas armadas estatales, narcotráfico y grupos delincuenciales diversos, constituyen la cara armada de la guerra, la cual tiene otros rostros escondidos en intereses de empresas, industriales, comerciantes, latifundistas, políticos, entre muchos otros actores, que intervienen, dinamizan y usufructúan del conflicto armado, sin que por ahora aparezcan suficientemente identificados. Se calcula que una tercera parte de los alcaldes y congresistas del país fueron promovidos por el paramilitarismo y cogobernaron con ellos (López, 2010). ${ }^{3}$ Muy lentamente se va poniendo en evidencia una triple alianza mafiosa, entre corrupción administrativa, bandas criminales herederas o próximas al paramilitarismo y el narcotráfico, que saquean las regalías de los municipios y se apropian de los recursos de salud, así como la participación de algunas empresas multinacionales como la Drummond y Chiquita Brands con grupos paramilitares. De esta manera, contar con mayores fortalezas institucionales, con presencia estatal y legitimidad del Estado, no garantiza la ausencia del conflicto armado, el cual se mantiene aunque se exprese sin confrontación violenta (Romero, 20II).

La guerra ha reconfigurado territorios a velocidades vertiginosas. Los lugares se vacían de pobladores y de sentido. Poblaciones fantasma, reconocidas y añoradas solamente por sus moradores e irrelevantes para la sociedad, van formando parte de historias anónimas sobre épocas de abundancia y tranquilidad, luchas de sobrevivencia y de autonomía. Así, la memoria de los lugares o toponimias va pasando del afecto o topofilia, a la topofobia, marcada por el temor y el dolor (Yori, 1999). La pérdida de lugar material y social de los desterrados se acompaña de una rápida pérdida de autoestima. Con el destierro no solo se pierde el fruto material de muchos esfuerzos, sino también su dignidad como vecinos, productores y ciudadanos.

3 En junio de 20Io, la Fiscalía reportó estar investigando a 400 políticos de elección popular, de los cuales una cuarta parte (IO2) son congresistas, habiendo sido condenados ya 25 de ellos (véase, López, 2010). 
La violencia sociopolítica más reciente ${ }^{4}$ fue instalando de manera silenciosa el desplazamiento forzado en la realidad nacional. El acumulado entre 1985 y 2012 se acerca a los seis millones de personas (5 701996$)$ (Codhes, 2013), cifra que equivale al $12 \%$ de la población nacional. ${ }^{5}$ Un promedio simple anual de algo más de 200000 personas y diario de 550 personas han quedado expuestas de manera vertiginosa a la miseria, el dolor y la búsqueda cotidiana de la sobrevivencia en medio de una "inestabilidad estable", esto es, de un desajuste permanente convertido en estructura (Lewkowicz, 2004). Todo ello genera fragmentaciones sociales profundas e irresueltas, potencialmente conexas con problemas crecientes de delincuencia social y marginalidad urbana, en medio de un grave despojo del territorio rural de campesinos, afros e indígenas.

El desplazamiento que en Colombia es un delito de lesa humanidad, se constituye en un "fenómeno masivo, sistemático, de larga duración y vinculado en gran medida al control de territorios estratégicos" (GMH, 2013:7I). Su gravedad ha situado al país como uno de los primeros lugares en el mundo. El desplazamiento forzado se da en el marco de múltiples violaciones de derechos humanos, de crímenes atroces, masacres, amenazas, desapariciones, crímenes sexuales y muchas vejaciones sobre la población que debe buscar la huida como forma de sobrevivir. El 97\% del territorio nacional, esto es I II6 municipios, ha registrado expulsión de población, con impactos diferentes, siendo la situación más crítica lo que ha sucedido en 139 municipios que tuvieron más de 10000 casos de desplazamiento forzado y que en conjunto concentran el $74 \%$ del fenómeno (GMH, 2013). El impacto, sin embargo, es diferente, de acuerdo con la rapidez y proporción de personas que salgan y también que lleguen. Algunos municipios han sido arrasados. Es el caso por ejemplo de San Carlos, Antioquia, que vivió el abandono total o parcial de 54 de sus 74 veredas y que pasó de tener 25000 habitantes a solo 5000 ( $\mathrm{GMH}, 2013)$. Lo vivido allí no es inusual en el país y se hace más frecuente en la medida en que la unidad de análisis de vecindario sea más chica.

Además del drama personal que suponen sus múltiples y profundas pérdidas y daños, el éxodo exige una ardua lucha cotidiana para volver a empezar en contextos muy adversos, plenos de estigmas y exclusiones. Pese a la nutrida normatividad e

4 Conviene señalar que la violencia bipartidista de mitad del siglo $\mathrm{xx}$ produjo en su momento cerca de dos millones de desplazados para una población de cerca de once millones de personas, lo cual da cuenta de la presencia constante del desplazamiento forzado en la configuración del país (Osorio, 2009).

5 Para 2012 se calcula que había en Colombia 46582000 personas, según www.obiee. banrep.gov.com a partir de datos del Dane. 
institucionalidad estatal, ${ }^{6}$ muestra fehaciente de la eficiencia simbólica de la norma ${ }^{7}$ (García, 2006), a la cual se suma una fuerte presencia de la cooperación internacional y de organizaciones no gubernamentales de diverso orden, son escasas las respuestas básicas oportunas y casi inexistentes los procesos de estabilización integral. Tratados con frecuencia como parias y expuestos a múltiples formas de revictimización que se acumulan, parecen condenados no solo a la "perpetuación de la pobreza para las generaciones presentes $y$, tal vez, futuras” (Ibañez, 2008:252), sino a la prolongación de relaciones de dominación y expoliación.

El conflicto armado ha producido una reconcentración de la propiedad rápida y creciente, a través del desplazamiento forzado y el despojo. La histórica concentración de la propiedad rural alcanza hoy un coeficiente de Gini de 0.86 (Ibañez y Muñoz, 20I2) al cual ha contribuido de manera importante la guerra. Amparados en la intimidación y en la complicidad de las autoridades locales y regionales, se han usurpado tierras a través de negocios legales e ilegales. Ocho de cada diez familias desplazadas

6 La legislación colombiana en materia de desplazamiento forzado es muy prolífica. La ley 387 de 1997 reconoció el fenómeno y la responsabilidad del Estado. El incumplimiento reiterado de todas estas disposiciones llevó a que a partir de ro8 expedientes de tutelas interpuestas por I I50 familias, la Corte Constitucional emitiera un fallo histórico con la Sentencia T-025 de 2004, la cual definió un estado inconstitucional de cosas en materia de desplazamiento forzado y ordenó al Estado una respuesta oportuna y eficiente. Con miras a garantizar ese proceso de cumplimiento se creó por parte de la sociedad civil la Comisión de Seguimiento a la Política Pública sobre Desplazamiento Forzado, la cual ha realizado tres encuestas nacionales y numerosos informes. A partir de revisiones periódicas de la actuación gubernamental (véase, www.codhes.org) la Corte se ha pronunciado a través de numerosos Autos para particularizar sobre cuestiones y poblaciones específicas. La Comisión ha desarrollado un trabajo de diagnóstico y análisis continuo de la situación de la población en desplazamiento forzado poniendo en evidencia la ausencia de políticas integrales oportunas y la falta de garantía de los derechos fundamentales de estas poblaciones. Más recientemente se emitió la ley I 448 de 201 que, en el marco de la justica transicional, busca "recomponer el tejido social, adoptando medidas efectivas en favor de las personas que han sufrido las consecuencias del conflicto armado" (Ministerio del Interior y Justicia, 20II:7).

7 Afirma que "en América Latina las incapacidades del sistema político suelen ser ocultadas bajo la práctica institucional del reformismo jurídico. Mientras más dificultades existen para cambiar una realidad social, más frecuente es que los intentos de cambios se consagren en fórmulas jurídicas. A falta de cambios reales se tienen cambios simbólicos" (García, 2005:6I) En ese sentido el derecho es un instrumento que facilita que las normas se creen para ser promulgadas y no para ser aplicadas, y pese a ello seguir manteniendo una alta legitimidad política. 
han tenido que abandonar sus tierras, pero solamente dos de ellas cuentan con escritura registrada, mientras que las demás no tienen documentos que respalden su tenencia o tienen sólo documentos privados. Este alto grado de informalidad en los derechos sobre las tierras de las víctimas del desplazamiento ha favorecido con frecuencia el despojo de por lo menos 5.5 millones de hectáreas (Garay y Barbieri, 20I2), lo cual equivale al Io.8\% de la superficie agropecuaria nacional.

Estas evidencias del sesgo rural que ha tenido la guerra se enmarca en un modelo de desarrollo rural inequitativo, excluyente, no sostenible y poco democrático, que concentra la propiedad y crea las condiciones para el surgimiento de múltiples conflictos (PNUD, 201I). La grave concentración de la tierra -la segunda en América Latina-, considerada como una condición objetiva y preexistente al conflicto armado, se ve exacerbada por éste al ritmo de las disputas por el control territorial por la vía de la fuerza y de las armas. En estas condiciones, es evidente que el poder económico derivado de la tierra configura una constelación de poder (García I973), con grandes rentas de orden político y social que potencian y amplían dicho poder, el cual se soporta además en fuertes estructuras armadas.

La guerra interna conlleva otras expresiones menos evidentes de control a la movilidad y libre circulación de la población en su propio país. Encontramos así dinámicas de desplazamiento forzado intraurbano, aún poco valoradas y atendidas, que dan cuenta de la continuidad del conflicto armado en las ciudades y el control de las poblaciones en barrios marginales (Grupo Memoria Histórica, 20II). De otra parte, se registran ejercicios de confinamiento como mecanismo de dominación armada por parte de actores legales e ilegales, para controlar y restringir la movilidad de las poblaciones, vigilar las dinámicas comerciales, desarrollando un claro ejercicio de biopoder y de gubernamentalidad, en tanto conjunto de instituciones, procedimientos, análisis y reflexiones, cálculos y tácticas que permiten ejercer poder sobre la población (Foucault, 2000). Desplazamientos forzados derivados de la fumigación y erradicación de cultivos de uso ilícito, como la coca, siguen siendo no reconocidos institucionalmente, pese a que se dan con frecuencia en el marco de operaciones armadas por tierra y aire (Tobón y Restrepo, 2009).

El desplazamiento forzado produce una severa desterritorialización rural que tiene como contraparte una dinámica de urbanización precaria y marginal, en donde los recién llegados son mirados a través de estigmas derivados de la polarización de la guerra. Vistos con una fuerte "sospecha moral" (Agier, 2002: 59) en tanto sobrevivientes, los campesinos ahora desplazados y víctimas de los actores armados son responsabilizados pues "por algo será que los persiguen". Son además estigmatizados tanto por el temor al "contagio de la violencia" como por lo que significan 
en la competencia por recursos estatales escasos. Los impactos y daños son vividos y manejados de manera diversa según experiencias relacionadas con el género, la etnia, la edad, la región, entre otros referentes. En ese sentido la Corte Constitucional ha emitido una cantidad importante de pronunciamientos ${ }^{8}$ con diagnósticos y recomendaciones específicas para que el Estado colombiano ofrezca respuestas institucionales con enfoque diferencial. En condiciones extremas y extrañas, su memoria evoca tiempos pasados de abundancia, libertad y buena vida en el campo. Añoran una tierra pródiga en recursos, en medio de una pobreza material desde los indicadores de NBI, pero con dignidad y alimento. Paisajes, comidas, rutinas, climas, libertades, vecindades, músicas, ritmos de vida, son referentes de ese pasado rural, extrañado e irrepetible que con frecuencia genera una importante revaloración de su identidad y de su vida campesina (Osorio, 20I0).

Con su nostalgia a cuestas, los desterrados reterritorializan nuevos lugares en medio de la precariedad y como advenedizos indeseables, tejiendo cotidianamente el entrecruce de tiempos y lugares, se van afirmando como sujetos que tienen derechos y que demandan no solo respuestas en términos de retribución, reconocimiento y participación (Fraser, 2008), sino también de reparación, exigencias aún esquivas. Aunque prevalece el temor, diversos procesos de memoria se realizan tanto por su propia iniciativa como por la de algunas instituciones (CNRR, Grupo Memoria Histórica, 2009), en respuesta a una necesidad de fortalecer la elaboración de sus duelos pendientes, buscando reconocimiento de su dignidad y de su lugar en la historia y la vida del país.

De manera insistente y colectiva reclaman, con distintos repertorios, ${ }^{9}$ respuestas efectivas y oportunas del Estado como un derecho y no como una limosna. Protestar en medio de la guerra implica correr riesgos antiguos y nuevos, como los que enfrentan los reclamantes de tierras, desafío que les ha costado el asesinato de más de 55 líderes y liderezas y el exilio de otros más (Codhes, 2013:5). Con frecuencia sus luchas y demandas se quedan en compromisos y planes incumplidos que configuran formas adicionales de revictimización ( $\mathrm{GMH}, 2 \mathrm{OI}$ ). Pese a tanta frustración, se van madurando las dinámicas, las confianzas y las búsquedas colectivas, se van

8 Se denominan Autos. Los más relevantes son el 25I de 2008 sobre protección de niños, niñas y adolescentes desplazados; el 092 de 2008 sobre protección a mujeres víctimas del desplazamiento forzado; el 004 de 2009 sobre comunidades indígenas y el 005 de 2009 sobre comunidades afrodescendientes. Véase, www.corteconstitucional.gov.co

9 Los repertorios más empleados tienen que ver con tomas institucionales, protestas públicas, invasiones masivas, acciones legales, marchas y bloqueos de carreteras (Bello y Osorio, 2008). 
aprendiendo lecciones de actuar en común y se van fortaleciendo redes no solamente entre desplazados, sino entre estos y otros grupos sociales, un espacio potencial y necesario que, sin embargo, es incipiente y tiene aún grandes desafíos.

El desplazamiento forzado continúa siendo expresión de la agudización del conflicto político, no solo por la magnitud de lo ya sucedido, sino por la ausencia de respuestas oportunas e integrales por parte del Estado. En 2013 existe un aire de optimismo relativo derivado de la expedición de la Ley de Víctimas y Restitución de Tierras (I448 de 2012), en el marco de los nuevos diálogos entre el gobierno y las Fuerzas Armadas Revolucionarias de Colombia, FARC. Entre tanto, la continuidad del conflicto armado se mantiene alimentado con acciones de las guerrillas, la vigencia de amenazas y crímenes por parte de nuevos grupos paramilitares y bandas delincuenciales, quienes mantienen cooptadas muchas estructuras de poder local y regional, así como de crímenes de Estado, ejecuciones extrajudiciales y otros abusos por parte de la fuerza pública.

La guerra en Colombia y su cara más visible: el desplazamiento forzado, ha sido excepcional en el marco latinoamericano. Sin embargo, las experiencias del conflicto armado, particularmente de Guatemala y Perú, han sido referentes obligados para discutir en torno a los procesos de diálogo, las realidades del postconflicto y las dinámicas de memoria, entre otros campos. Visto desde la existencia de grupos guerrilleros que quieran tomar el poder por las armas, no hay otro caso vigente en el continente. Sin embargo, si se mira desde la presencia de ejércitos paramilitares y delincuencia organizada, como los grandes cárteles del narcotráfico, no hay fronteras suficientes que permitan aislar estos grupos, pues se sitúan en el orden transnacional, al igual que los mercados ilegales que los alimentan y que se mantienen muy articulados con los mercados legales. Cada vez es más claro el papel y el lugar que están ocupando estos poderosos actores en la vida de muchos países. La guerra contra los cárteles del narcotráfico representa hoy en día una crítica situación en México, especialmente en algunos de sus estados cercanos a la frontera norte, con numerosos desplazamientos forzados que apenas empiezan a ser estudiados y valorados (IDMC, 200I; Job, 20II).

En medio de la impunidad que configura una aparente y frágil democracia es claro que, en el caso colombiano, la guerra ha sido una eficiente estrategia para fortalecer los procesos de concentración de la tierra y de los recursos en general. Una guerra prolongada y de baja intensidad se corresponde con una democracia formal de baja intensidad que, en nombre del bien común, favorece la entrada de grandes capitales y la reconversión de los territorios hacia esos intereses. En ese sentido, el 
desplazamiento forzado ha sido una constante histórica motivada por la búsqueda de acumulación por desposesión (Harvey, 2004).

\section{Despojos y destierros causados por obras de infraestructura y proyectos minero-energéticos y agroindustriales}

De muchas maneras, guerra y capital en una alianza perversa están incursionando territorialmente con éxito, para disputar territorios habitados por diversos pobladores rurales en el país. Su accionar ha sido amplio y eficiente. Su impacto se sitúa en dimensiones múltiples que atañen al sentido profundo del ser y de la vida. Un proceso de pauperización creciente se instala ampliando el empobrecimiento y la miseria, distribuyéndolos en los márgenes de las ciudades, vulnerables a los desastres y a la descomposición social. Si bien tienen dinámicas específicas, los incluimos en una misma categoría porque, además de provocar impactos importantes en el despojo y el destierro, tienen cuatro características similares: generan fuertes impactos ambientales, tienen ritmos establecidos y programados, constituyen una estrategia para el crecimiento económico de intereses privados y el Estado regula a favor de sus intereses.

Las obras de infraestructura corresponden especialmente a embalses y represas, pero también a vías, canales, distritos de riego, entre otras. Se calcula que diez millones de personas se desplazan anualmente en el mundo por estas obras financiadas por la banca internacional, la cual ha definido algunos impactos que deben ser tenidos en cuenta para la indemnización y el reasentamiento de las poblaciones afectadas: la pérdida de la tierra, del trabajo, de la vivienda, de acceso a la propiedad común, inseguridad alimentaria, marginalización, aumento de la morbilidad y mortalidad y desintegración social, todos ellos constantes en las diferentes migraciones forzadas (Cernea, 1997).

En Colombia han sido diversas las experiencias de este tipo de obras. Una de las más relevantes por tamaño es la represa de Urrá, situada en el municipio de Tierralta, Córdoba, en el norte del país. La represa recoge fundamentalmente aguas del río Sinú, que nace en el Nudo de Paramillo al sur del departamento de Córdoba y recorre 415 kilómetros hasta el mar Caribe donde desemboca, irrigando un fértil valle que fue habitado por los zenúes, conocidos como "cultura anfibia" o "sociedad hidráulica”, por el conocimiento y manejo eficiente del agua. Esta obra, además de las comunidades campesinas vecinas, afectó sustancialmente a la comunidad indígena Embera, en un proceso que cruzó la construcción de esta obra con el 
conflicto armado y que le costó la vida a I5 de sus líderes y a más de 40 miembros de la comunidad. Si bien la idea comienza a circular hacia la década del cuarenta, sólo a mediados de I99I se expidió un concepto técnico favorable para el comienzo de las obras. En cincuenta años que tardó el proyecto en concretarse, nunca fue consultado con las comunidades indígenas cuyos territorios se iban a ver afectados directamente. Ya en funcionamiento, la realidad muestra el empeoramiento de condiciones de vida de los pobladores rurales y el aumento de la concentración de la tierra y los recursos (Rodríguez y Orduz, 2012: 20).

Otro caso se ubica en el Oriente antioqueño, una subregión del centro del país, cuya población supera el medio millón de personas. Produce alrededor del 30\% de la energía del país con sus seis centrales hidroeléctricas: El Nare, San Carlos, y otras cuatro menores. "Instalar este complejo significó inundar las mejores tierras agrícolas, propiciar el decaimiento de la actividad agropecuaria del minifundio campesino, y un auge de la actividad turística, hoy en vilo por el conflicto armado que ha forzado los desplazamientos de pobladores, el abandono de parcelas cultivables y el golpe sistemático a la infraestructura energética" (Jaramillo, 20I0: 29). Además de los graves daños ambientales, los embalses han facilitado el despojo a los campesinos de tierras cultivables sin la debida y oportuna reparación. La transformación de esta importante región en un territorio arduamente disputado por guerrillas (ELN y FARC), autodefensas, narcotraficantes y ejército ha convertido a la población civil en blanco de sus acciones y agrava el flujo de población desplazada hacia las cabeceras municipales. La dinámica del conflicto armado que se ha manifestado a través de numerosas masacres, desapariciones, afectados por minas antipersonas, desplazados y menores reclutados, guarda relación con este tipo de obras y con el manejo dado a las tensiones sociales que allí se generaron. Se calcula para la región IO2 2 Io desplazados y 2 I 790 hectáreas abandonadas, lo cual corresponde al $22.44 \%$ de la tierra que ha sido abandonada en todo el departamento de Antioquia (Moncada, 20II).

Muchas otras obras están proyectadas: las represas "El Cercado" sobre el río Ranchería y del río Guatapurí, sector Los Besotes, en la Sierra Nevada de Santa Marta, en el norte del país (Coronado, 2010); la represa sobre el río Quimbo que inundará un fértil valle productor de alimentos en el sur del Huila, afectando a seis municipios y la represa del río Sogamoso en Santander. Todas están siendo cuestionadas por movimientos socioterritoriales que buscan impedir su construcción.

Esta dinámica no es ajena al conjunto de países de América Latina, con tendencias relativamente parecidas: impactos violentos e irreversibles en especies $y$ ecosistemas, afectaciones a la salud, la alimentación y pérdida de formas de vida tradicionales, desplazamientos forzados, ausencia de consulta y participación pública, 
falta de acceso a información libre, adecuada y oportuna, criminalización de la protesta y afectaciones a los derechos de los pueblos indígenas y tribales (Asociación Interamericana para la Defensa del Ambiente, 2009). Una diferencia sustancial con el caso colombiano se deriva de la sobreposición de las dinámicas de guerra en todos estos impactos, profundizándolos, en particular en lo que tiene que ver con la presión sobre las comunidades y en el manejo y tratamiento de las manifestaciones colectivas de protesta.

Los proyectos minero-energéticos y agroindustriales constituyen otra incursión del gran capital, fuertemente apoyados por el gobierno colombiano en el marco de una nueva tendencia-mandato en América Latina. Se trata del Consenso de los commodities que se fundamenta en el extractivismo de materias primas para la exportación masiva y que reemplaza al Consenso de Washington basado en la valorización financiera (Svampa, 2012). A partir de 2002, el gobierno colombiano entró en una dinámica acelerada de concesiones del subsuelo de la nación a firmas nacionales y empresas multinacionales, línea que se ha priorizado al punto que se sitúa como una de las cinco locomotoras de la economía nacional en el gobierno actual. El camino ya transitado de la reprimarización tiene un fuerte impacto en la sostenibilidad ambiental y social, va de la mano de la inversión extranjera, a la cual se le ofrecen las mejores ventajas comparativas, como baja tasa efectiva de impuesto para utilidades corporativas, ausencia de impuesto de retención sobre ganancias giradas al extranjero, deducciones de impuesto sobre inversiones fijas, entre otras (Fierro, 20II).

Tales empresas han apelado a prácticas de seducción y de coacción que apenas se están reconociendo. La disponibilidad de ingentes recursos para distribuir entre las comunidades, que acallan sus inconformidades y buscan desde el primer momento generar una alianza por la vía de las prebendas, ha sido señalada por el pueblo Nasa del norte del Cauca, y colectivos de Cajamarca (Tolima), Santurbán (Santander), el Cesar y la Guajira. La estrategia inicia con acuerdos con las autoridades locales y regionales bajo promesas de aportes para obras del municipio, patrocinio de actividades culturales y ofertas de empleo para la población. El uso de la fuerza pública para respaldar los intereses de las empresas en contra de las reacciones y protestas de las comunidades, ilustra muy bien el papel del Estado liberal para proteger el capital, como ha sucedido, por ejemplo, con la comunidad Embera y su defensa del cerro Careperro, sitio sagrado e invadido por la Muriel Mining Corporation (Osorio y Herrera, 20I2). Varios pueblos y caseríos han sido forzados a abandonar sus lugares, porque estorban la expansión de la explotación carbonífera de la Drummond en el nororiente del país, tal como le sucedió al pueblo de Tabaco, en el Cesar. La propuesta 
de reasentamientos involuntarios, pese a la apariencia de producir mejoría en las condiciones de vida, impone modelos urbanizados de vivienda que se distancian de las actividades productivas rurales existentes, en medio de una grave contaminación ambiental, generando una rápida descomposición de las dinámicas socioculturales que hace de estas soluciones procesos poco sostenibles.

Junto con los proyectos de concesión para la explotación minero-energética, está la actividad agroindustrial, especialmente de palma aceitera. Este cultivo que ha tenido un crecimiento continuado a partir de la década de los años sesenta, supera actualmente las 500000 hectáreas y tiene proyectado sextuplicar, en una alianza expresa con los gobiernos para ampliar y establecer este tipo de monocultivo de plantación como fuente de dinamización y modernización del sector rural. Un caso emblemático de fusión de intereses entre cultivos agroindustriales de palma aceitera y grupos paramilitares es el de las cuencas de los ríos Jiguaminadó y Curvaradó en Chocó, territorios colectivos de poblaciones afrodescendientes en donde se impuso un proyecto económico-paramilitar basado en la palma, a través de la creación de grupos asociativos de trabajadores, para promover la economía local, creando condiciones de lealtad, autoridad y dependencia. Pero además, el Bloque paramilitar Élmer Cárdenas ha dividido y atentando contra organizaciones comunitarias e indígenas y afrocolombianas existentes, a través del desplazamiento de cerca de I 500 personas y el asesinato de I20. El Instituto Colombiano de Desarrollo Rural, Incoder, determinó en 2004 que el $93 \%$ de cultivos de cuatro de las más grandes empresas se levantaban en tierras de comunidades negras. El caso sigue impune, pese a que investigaciones posteriores han señalado que recursos del Banco Agrario y de la Cooperación Internacional han sido destinados a la financiación de estos proyectos.

Obras de infraestructura, megaproyectos minero-energéticos y grandes explotaciones agroindustriales constituyen una fuente constante de expulsión interna y despojo de campesinos, indígenas y afrodescendientes en el país. El contexto de guerra camufla y favorece amenazas, intimidaciones y asesinatos cuya responsabilidad se asigna exclusivamente a los actores armados ilegales eximiendo a empresas y empresarios que los financian para favorecer sus intereses. Con matices, gobiernos latinoamericanos de derecha y de izquierda mantienen sus apuestas por esta inflexión extractivista, que incluye la doble dimensión minero-energética y agroindustrial, además de los proyectos de infraestructura previstos por la Iniciativa para la Integración de la Infraestructura Regional Suramericana, IIRSA, en materia de transporte y comunicaciones, "un modelo tendencialmente monoproductor, que desestructura y reorienta los territorios, destruye la biodiversidad y profundiza el proceso de acaparamiento de tierras"(Svampa, 2012:18). 
Frente a la magnitud de estas amenazas, movimientos territoriales comienzan a articularse con movimientos ambientales, potenciando las luchas sociales en diversos rincones de América Latina y conjugando demandas rurales y urbanas que han ido alcanzando algunos logros relativos. La denominada ambientalización de las luchas sociales se compone de múltiples colectivos con actores y repertorios amplios y diversos, que favorecen el diálogo de saberes, incluyendo la valorización de los saberes locales (Svampa, 20I2). Jóvenes y mujeres son protagonistas en estas dinámicas, que articulan lo global y lo local, el campo y la ciudad, a través de redes de territorios, que van produciendo diagnósticos comunes centrados en la defensa de la vida representada en el agua, la tierra y la naturaleza. Las luchas son lentas, difíciles pero esperanzadoras.

\section{Éxodos causados por desastres ambientales}

Lo que se conoce como desastres ambientales son manifestaciones del medio ambiente ante el acumulado de prácticas que lo dañan de manera irreparable. Son usualmente sucesos imprevistos y devastadores que producen emergencias caracterizadas por su "alto riesgo vital de un grupo en relación con sus capacidades y recursos" (Berinstain, 1999: 2I). Se prevé que huracanes, tsunamis, terremotos, inundaciones entre otros muchos, darán origen a los millones de refugiados ambientales que vendrán. En una década, 2000 millones de personas se han visto afectadas por catástrofes naturales y se calcula que habrá cerca de 2II millones anuales, esto es, cinco veces los afectados por los conflictos armados (ACNUR, 2006), en el marco de la universalidad del riesgo y la globalización del peligro, como parte inherente del "volcán civilizatorio" (Beck, 2006).

Sin embargo, no es fácil definir cuántos de ellos sufren el destierro por tales causas, dado que éstas se mezclan de manera compleja con factores de orden socioeconómico y político. Con frecuencia sociedades en crisis generan migraciones tanto políticas, como económicas y ambientales. Algunos estudios señalan que en 2050 serán entre 200 y 700 millones de personas las que se podrán denominar como refugiados ambientales, una cifra realmente grave:

Las consecuencias de esta arremetida capitalista contra los últimos territorios del planeta, que aún subsisten por fuera de la lógica de acumulación sin fin, se hacen sentir sobre todo en las regiones periféricas del mundo. Es ahí donde los campesinos expulsados de sus tierras, ahora destinadas a usos más rentables', pasan directamente 
a la pobreza o a la indigencia; y es ahí donde un encarecimiento de los alimentos básicos se traduce inmediatamente en hambre. Es ahí también donde el calentamiento global produce millares de muertos mediante sequías, desertificación, inundaciones o tormentas [...] La crisis climática, invariablemente, tiene graves consecuencias sociales y económicas, agudizando otras crisis, creando nuevos mercados especulativos, y de esa manera, genera un círculo aparentemente interminable de crisis. Desde la periferia, esta múltiple crisis se ha reconocido como crisis civilizatoria" (Lang, 20II 8).

En el marco de tal crisis la desigualdad de los impactos y de la capacidad para responder y prevenir son también profundamente desiguales. Recientemente se reconoce que los países en desarrollo deberán soportar entre el 75 y el $80 \%$ de los daños del cambio climático, pese a que, como América Latina y el Caribe, emitan menos del Io\% del total de emisiones de gases de efecto invernadero (GEI) hacia la atmósfera (Lara, 20I2).

Esta realidad, sin embargo, es leída y reconocida en medio de un discurso que despolitiza su comprensión, al privilegiar su ubicación en el orden puramente biofísico, de manejo del riesgo por desastres y la asistencia humanitaria. Las referencias a la desigualdad y la injusticia que están en la base de los desastres ambientales y de los destierros que allí se originan, son ignoradas, concentrando la atención en la vulnerabilidad resultante. Ello reduce sustancialmente la reflexión crítica sobre los alcances de las respuestas, las políticas y su orientación, ratificando tácitamente las comprensiones de la población sobre su mala suerte al estar en el lugar equivocado o el castigo divino. Las exigencias y compromisos de las empresas, los gobiernos y la sociedad hacia acciones de tipo preventivo siguen quedando minimizadas, lo cual facilita su repetición cíclica.

La categoría de refugiado ambiental surge de esta realidad creciente y está en el centro del debate con diferentes apuestas. El Programa de Medio Ambiente de Naciones Unidas diferencia dos categorías de migrantes ambientales: i)los desplazados ambientales, que son temporales pues seguramente podrán retornar a su lugar de salida, luego de fenómenos como temblores, huracanes o erupciones volcánicas; ii) los desplazados permanentes que se dividen en dos grupos: los que salen porque sus territorios han sufrido cambios drásticos, como la construcción de grandes obras de infraestructura, y los que salen por una degradación progresiva (Castillo, 20II). Categorías utilizadas por las tradicionales migraciones internacionales económicas y forzadas son retomadas para aplicar a las nuevas realidades derivadas de los desastres ambientales. Refugiados, desplazados y migrantes ambientales son categorías que empiezan a emplearse en medio de discusiones más por cuestiones políticas 
que semánticas, estrechamente relacionadas con "quién se debe hacer cargo de las responsabilidades emanadas de los movimientos poblacionales" (Castillo, 20II:16). Colombia tiene índices de vulnerabilidad importantes frente a los efectos del cambio climático, que se traducen principalmente en inestabilidad de los suelos pendientes $y$ riesgo de inundaciones en las zonas planas.

Durante los últimos 40 años los desastres han ocasionado pérdidas anuales de US\$ 177 millones. Entre 1970 y el 201 se han registrado más de 28 ooo eventos desastrosos, de los cuales cerca del $60 \%$ se reportan a partir de la década de 1990. Además, durante el 2010 y el 20II, en tan solo I5 meses, se alcanzó una cifra equivalente a la cuarta parte de los registros y los muertos de la década anterior (Banco Mundial, 2012:3).

Una mirada a la historia reciente da cuenta de desastres, algunos de los cuales no se relacionan directamente con un daño antrópico como los terremotos, muestra una lista que incluye el de Tumaco en la costa del Pacífico (1979), el de Popayán, Cauca (1983), la erupción del volcán nevado del Ruiz que sepultó a Armero (1985) y el de Armenia (1999) que afectó al eje cafetero, todos con numerosas pérdidas en vidas y en costos materiales.

Otros fenómenos de tipo cíclico como las inundaciones y deslizamientos de tierra, resultan del uso inadecuado del suelo, de las fuentes de agua y la deforestación. Ejemplos graves corresponden a los deslizamientos ocurridos en Villatina, barrio de Medellín (1987), el deslizamiento en Páez, Cauca (2008). Una emergencia de orden nacional surgió de una fuerte ola invernal en 2010 y 2011 . El cálculo de afectados a mediados de mayo de 201 alcanzó 3318564 personas y en varios departamentos el invierno afectó más del 75\% de la población, destruyendo viviendas, cultivos, vías de comunicación, acueductos, alcantarillados y obligando a las personas a salir de sus lugares. Un balance institucional reportó que cerca de 125000 personas se desplazaron, 524 resultaron heridas, 444 murieron y 74 más desaparecieron (Barajas y Arcos, 20II: 7).

En el marco de esa ola invernal, el municipio de Gramalote, Norte de Santander, debió ser abandonado en 2010 porque un fuerte alud de tierra sepultó cerca de 850 viviendas. Luego de casi tres años y medio los gramaloteros siguen viviendo en albergues, con familiares y algunos otros pagando arriendos de viviendas precarias, sintiendo el peso del abandono, la falta de participación y las demoras inusitadas en los estudios técnicos que se combinan con intereses particulares que han cuadruplicado los costos estimados, en medio de un proceso de especulación soterrada de los precios de la tierra. Algunos han ido consiguiendo lotes cercanos a su antigua 
residencia y han comenzado a construir, cansados de esperar respuestas duraderas, mientras unas pocas familias han retornado al poblado para habitar en medio de los escombros y de la soledad.

Los sectores de población más afectados por estas olas invernales corresponden usualmente a poblaciones ribereñas de los ríos, que tienen viviendas precarias y en las ciudades poblaciones que han construido sus barrios en zonas marginales, desprovistas de adecuadas redes de servicios domiciliarios. Es decir, son migrantes internos empobrecidos, voluntarios o forzados, que en su búsqueda para evitar la muerte, para escapar a las amenazas y al hambre, emprenden el camino en condiciones de tal precariedad que facilitan nuevos riesgos en otros lugares. La carencia de respuestas institucionales oportunas e integrales que atiendan efectivamente sus condiciones de vida, les lleva a engrosar los ejércitos laborales disponibles con bajos salarios, cerrando claros circuitos de perdedores y de ganadores de los éxodos internos que, con frecuencia, deben extenderse más allá de las fronteras (Osorio, Mejía y Restrepo, 2010).

Los estudios sobre las migraciones provocadas por desastres y crisis ambientales constituyen un campo emergente de estudio en Colombia y en América Latina. La Red de Estudios Sociales en Prevención de Desastres en América Latina creada en 1992 y la Red Género y Desastres en América Latina y el Caribe en 20II, son una muestra de ello. ${ }^{10}$ La huella ambiental está ampliando el umbral migratorio interno e internacional, pero aún desconocemos toda la complejidad y entrecruce de hechos explícitos e inmediatos con acumulados históricos que quedan invisibilizados. Lo más grave, sin embargo, es el poco compromiso concreto para reorientar las dinámicas del modelo económico y del sistema mismo, que siguen repitiendo y agravando condiciones para el destierro, cuyo denominador común es la salida sin retorno y sin ilusión.

\section{Reflexiones finales}

Desplazamiento forzado, destierro, despojo, éxodo, exilio, desarraigo, refugio ambiental son algunas de la categorías con las cuales se nombra y reconoce la salida forzada de población, por razones de conflicto armado interno, desastres ambientales, obras de infraestructura y proyectos minero-energéticos y agroindustriales. Quienes sufren estas situaciones límite, se sitúan en medio de dos sentidos contra-

10 Véase, respectivamente www.desenredando.org y www.redgeneroydesastres.org 
dictorios: por una parte, se configuran en sujetos formales de derechos y atención institucional prioritaria dada su vulnerabilidad y, por la otra, se convierten en vecinos sospechosos, estigmatizados y rechazados. Las categorías institucionales y sociales que se acuñan luego de largas luchas y reivindicaciones, se vuelven nociones que se instalan no solo para designar una situación objetiva, la de aquel que ha llegado a otro sitio en condiciones límite de sobrevivencia y con graves pérdidas y daños, sino sobre todo para "operar una discriminación semántica, aplicada exclusivamente a los sectores subalternos de la sociedad" (Delgado, 1999: 92).

Denominar estas situaciones límite y con ello reconocerlas suficientemente en su complejidad es un reto permanente. La experiencia en el caso colombiano con el desplazamiento forzado por el conflicto armado, permite asomarnos muy rápidamente y con fines ilustrativos a este campo. Por una parte está el "desplazamiento forzado", una categoría institucional e internacional que marca su diferencia con la categoría de refugiado al situarse en el marco de la frontera del país de origen, que se adoptó en el país en 1997 y muy rápidamente se banalizó. En este momento, se impone con la ley 1448 una nueva categoría, la de víctimas, lo cual constituye potencialmente una vía para su extinción, en medio de una mucho más genérica que volvería a invisibilizar una realidad específica que costó mucho posicionar. El "destierro" es otra denominación que se ha utilizado y que sin haber sido fuente de debates conceptuales, tiene una enorme fuerza semántica. En su acepción clásica es entendido como un "mecanismo institucionalizado de exclusión política" (Roniger, 20II:I) y su recorrido conceptual e histórico ha estado articulado a dinámicas que se relacionan más con el asilo y el refugio. Su uso, en el caso colombiano, tiene un sentido más metafórico, pues además refleja de manera muy clara no solo la salida forzada de la tierra, sino la pérdida material de ésta. El "desarraigo" es otra noción que se ha definido como una "expresión contemporánea de un proceso histórico de estructuración social caracterizado por la imposición de modelos económico-políticos, colonizantes, inequitativos, discriminantes, que han exigido el sometimiento de las mayorías" (Lozano, 2003). Finalmente, pero no menos importante, está la categoría de "despojo", que no reemplaza a las anteriores sino que se constituye más bien en una figura complementaria que suele acompañar la experiencia del desplazamiento forzado. Se trata de un "proceso por medio del cual involuntariamente un grupo o un individuo se ven privados material y simbólicamente por fuerza o coerción, de bienes muebles e inmuebles, lugares y/o territorios sobre los que ejercían algún uso, disfrute, propiedad, posesión, tenencia u ocupación para la satisfacción de necesidades" (CNRR, Grupo Memoria Histórica, IEPRI, 2009: 30). Más que un fin es un medio a través del cual se procuran objetivos diversos ligados a los intere- 
ses de quien ordena las relaciones de poder y violencia en una región, buscando su favorecimiento particular. No obedece a un repertorio unívoco de lógicas y combina violencia física con apelación a figuras jurídicas, además de muchas otras estrategias. $\mathrm{Su}$ desarrollo en términos no solo del concepto sino de las formas y medios por los cuales se ha sucedido el despojo en el país, constituye un aporte significativo para avanzar en la comprensión y reconocimiento de los impactos de la guerra en el país.

¿Qué de este recorrido puede ser útil para reconocer y nombrar las experiencias de migración forzada que se han dado por las obras de infraestructura y por los desastres ambientales? ¿Cómo denominar y comprender los muchos nexos que tienen estas tres dinámicas, sin desconocer sus particularidades? El desafío de nombrar aquello que a veces parece innombrable, para cuestionar las categorías existentes y para buscar nuevos sentidos que recojan no solo esas nuevas realidades sino también las propias interpretaciones y formas de autorreconocimiento que hacen las personas que sufren y lidian cotidianamente con esta dolorosa realidad, se mantiene vigente.

En el cierre de estas reflexiones interesa resaltar tres factores de similitud entre las modalidades de migración forzada interna ya expuestas. Uno es el vínculo con efectos, justificaciones y promesas de desarrollo, pero más exactamente de crecimiento económico. En tanto "concepto maestro" rico en su significación, pero también "oscuro, incierto, mitológico y pobre" como lo plantea Morin (1995ः 390), el desarrollo tiene múltiples e incompatibles lazos con los procesos de destierro y abandono forzado de la tierra y el territorio. A diferencia de las migraciones voluntarias que han sido comprendidas y explicadas de manera muy articulada con las dinámicas económicas, las forzadas parecen con frecuencia desconectadas de esta discusión. Las realidades de los éxodos en Colombia y Latinoamérica muestran un trasfondo directamente relacionado con la acumulación económica que alimentan las guerras y la incursión de grandes capitales en el extractivismo minero y agrícola. El ciclo se completa en la marginalidad urbana en donde ingresan a mercados de trabajo diferenciados marcados por la sobreexplotación de la mano de obra, que refuerzan dinámicas de crecimiento excluyente. Desembocan así en el mismo "vertedero" y no "se verán libres de la tormentosa sensación de transitoriedad, indefinición y provisionalidad de cualquier asentamiento" (Bauman 2005:I0I). Geografías del empobrecimiento y la miseria coinciden con geografías de las migraciones forzadas, que replican relaciones de dominación y segregación.

Un segundo factor es el papel fundamental del Estado frente a la prevención, atención, reconocimiento, las respuestas oportunas y las disposiciones jurídico administrativas con estas poblaciones despojadas. Sin embargo, como en el caso colombiano, buena parte de las causas del destierro y el despojo se dan precisamente 
por un Estado debilitado, cooptado por estructuras criminales (López, 2010), hecho que deja en clara desprotección estas poblaciones y para quienes el mero ejercicio de exigencia, vigilancia y control se vuelve menos viable dado que las condiciones institucionales y las relaciones de poder son adversas a las víctimas. Habitar el país de origen no es garantía de la protección real de derechos ni de relaciones sociales de equidad. Muchos de los inmigrantes forzados se sienten tratados como extraños en su propio país. Relaciones identitarias de pertenencia por origen, historia, lengua y otras prácticas culturales, en particular de orden étnico, pueden marcar tantas y tan profundas distancias en una misma sociedad nacional que podrían equipararse a las relaciones asimétricas entre nacionales y extranjeros pobres. Huyen cargando culpas que la sociedad y el Estado les endilga, en búsqueda de un nuevo lugar físico y social, un camino que para muchos no parece tener fin.

Un tercer factor tiene que ver con las vivencias diferenciadas de quienes sufren el despojo y el destierro, de acuerdo con su condición y posición según género, edad, pertenencia étnica, región, experiencia de liderazgo, entre muchas otras circunstancias. Ese marco diferencial es importante reconocerlo para evitar su homogeneización y poder construir respuestas que correspondan a sus demandas de orden sociocultural. Pero no solamente para reconocer la diferencia, sino sobre todo la desigualdad que la acompaña y que va a marcar formas diversas de afectación, daño y manejo derivados del destierro, el despojo y el desastre. Las experiencias límite de este tipo de éxodos requieren de lecturas situadas por parte de funcionarios e instituciones que los apoyan, de manera que la crisis pueda ser manejada no solo como problema sino como oportunidad, a través de una relación respetuosa que sitúe al afectado desde un principio como una persona normal en condiciones anormales, un sujeto político, reflexivo y crítico y no un mero objeto pasivo de servicios y ayudas, evitando causar nuevos daños que lo revictimicen a través de la relación institucional.

Las migraciones forzadas internas producidas por el conflicto armado, por obras de infraestructura y por desastres ambientales tienen también por lo menos tres claras diferencias. Un primer factor diferenciador son las responsabilidades. El destierro provocado por la guerra tiene claras implicaciones políticas y de responsabilidad de gobernantes y de Estados, grupos armados y personas concretas, a los cuales es posible exigir procesos de justicia, verdad y reparación, como prerrequisito de los potenciales procesos de posguerra y reconciliación. Las responsabilidades se pueden establecer con mediana claridad en el caso de las obras de infraestructura y de los megaproyectos minero-energéticos. Sin embargo, dicha responsabilidad y causalidad se torna mucho más difusa y esquiva en los desastres ambientales, dados sus vínculos con causas lejanas y acumulativas de tiempos largos (Castillo, 20II). La 
lectura religiosa de destinos ya trazados y decisiones divinas, a manera de castigos para el mundo, contribuye a evitar siquiera la pregunta por los responsables.

Las representaciones sociales que se construyen frente a los sobrevivientes y sus autopercepciones son un segundo factor. Ello se relaciona profundamente con los referentes identitarios que acompañan los éxodos y que trasladan y construyen estigmas que marcan el reconocimiento del otro y la construcción de sociabilidades necesarias para recomenzar sus vidas. El forastero es visto como "enemigo interior", pues reúne en sí mismo al pobre y al extranjero, fruto de una trayectoria errante y sospechosa (Simmel, 1979). Los sobrevivientes de la guerra, dado el peso desestructurador que tiene el conflicto armado en el tejido social, suscitan una mirada que los identifica en medio de la relación amigo-enemigo. El daño intencional y consciente que causa la guerra, amenaza y fragiliza el respeto por los sobrevivientes en tanto ciudadanos dejando en estos una visión más negativa del mundo (Berinstain, 1999). Muy lentamente las víctimas logran constituirse efectivamente en la memoria moral de la sociedad, en la medida que su historia particular posicione en el centro del debate la dignidad de la vida desde la experiencia de la muerte (Mate, 2005). Quienes deben desalojar sus tierras y territorios en razón de obras de infraestructura y megaproyectos, se configuran como pobres afortunados pero siempre insatisfechos, pues las grandes cifras de las compensaciones económicas que hacen las empresas en sus juegos mediáticos, así lo muestran. Quienes huyen por los desastres naturales, si bien pueden recibir con mayor facilidad muestras materiales de solidaridad en los primeros momentos, se constituyen en pesadas cargas que los señalan como pobres inactivos y dependientes, sin iniciativa para resolver sus problemas. Como víctimas del azar y la mala suerte, su reconocimiento es menos negativo e inculpador que el de las víctimas del conflicto armado. Su ingreso a las cadenas de miseria y filantropía se mezcla rápidamente con las promesas clientelistas y los intereses oportunistas de los gobernantes que de manera reiterada se comprometen a resolver sus problemas.

Un tercer factor clave que muestra matices significativos es el de los procesos de construcción y reconfiguración de sí mismos como sujetos políticos. Sin duda, las biografías y prácticas políticas previas van a ser factores que facilitan procesos de exigencia y seguimiento a las instancias encargadas y responsables de brindar respuestas inmediatas y permanentes en su nueva condición. Es decir, la existencia previa de marcos de sentido comunes (Chihu y López, 2004) que permita identificar la situación como injusta identificando responsabilidades, será fundamental para facilitar con mayor rapidez procesos reivindicativos de orden colectivo. La huida intempestiva con que se abandonan los lugares en el conflicto armado y los desastres naturales, genera una situación de shock muy fuerte que puede dispersar las bús- 
quedas de respuesta. Pero además, la deslegitimación con que son vistos los análisis críticos en Colombia por considerarse subversivos, ha contribuido a despolitizar estos marcos, pues además tener un pensamiento y un liderazgo reivindicatorio sigue siendo factor de riesgo. En el caso de los afectados por la ola invernal, parece haber un ejercicio político menos activo; los marcos de sentido situados en una decisión divina limitan su comprensión frente al problema estructural, sus adversarios y las posibles soluciones.

Sin duda, la expresión política en condiciones límite constituye un campo potencial tanto en la prevención, tal como se señalaba con respecto a los movimientos en defensa del territorio en varios lugares del país frente a las exploraciones mineras, como en la veeduría y control de las dinámicas institucionales ante el incumplimiento de sus responsabilidades. No obstante, la respuesta colectiva y organizada tiene un alto grado de exigencia, que se suma a las ya duras tareas de superación de sus propios duelos y la respuesta cotidiana para sobrevivir en condiciones muy difíciles en entornos adversos.

A diferencia de las diásporas de la esperanza, fruto de la migración enmarcada en la búsqueda de un mejor futuro, el destierro y el despojo se sitúan como diásporas del terror y desespero (Appadurai, 200I). Forzados por las urgencias de los recursos y por las exigencias de los trámites, van rehaciendo una noción de ciudadanía potencial, que implica su condición de sujetos de derecho -así no los disfrute-, una percepción del Estado como el "adversario" al cual reclamarlos - así no lo pueda hacer- $y$ una pertenencia a una sociedad nacional mayor -así los rechace.

\section{Bibliografía}

ACNUR

2006 La situación de los refugiados en el mundo. Desplazamientos bumanos en el nuevo milenio, Icaria, Barcelona.

AIDA

2009 "Grandes represas en América ¿Peor el remedio que la enfermedad? Principales consecuencias ambientales y en los derechos humanos y posibles alternativas", en Asociación Interamericana para la Defensa del Ambiente, <http://www.aida-americas.org/sites/default/files/ InformeAIDA_GrandesRepreseas_BajaRes_I.pdf $>$ [agosto de 20I3]

Agier, Michel

2002 Aux bords du monde, les réfugiés, Flammarion, París, 187 pp. 
Appadurai, Arjun

200I Aprés le colonialisme, Payot, París, 322 pp.

Archila, Mauricio, Ingrid Bolívar y Álvaro Delgado

2006 Conflictos, poderes e identidades en el Magdalena Medio, 1990-2001, Cinep, Bogotá, 577 pp.

Bales, Kevin

2000 La nueva esclavitud en la economía global, Siglo xxi, Madrid, 317 pp.

Banco Mundial

2012 Análisis de la gestión del riesgo de desastres en Colombia: un aporte para la construcción de políticas públicas. Banco Mundial, Bogotá, 4II pp.

Barajas, Yenni y Pedro Arcos

201 "Desastres por inundación en Colombia: Retos y perspectivas para la salud pública", en Revista Española de Emergencias y Desastres, núm. I, Pp I-I5.

Bauman, Zygmunt

2005 Vidas desperdiciadas. La modernidad y sus parias, Paidós, Ibérica, Barcelona, I7I pp.

Beck, Ulrich

2006 La sociedad del riesgo, Paidós, Barcelona, 393 pp.

Bello, Martha Nubia y Flor Edilma Osorio

2008 "Acciones colectivas de la población desplazada", en Sandro Jiménez (coord), Desplazados, víctimas en permanente transición: repensar la relación conflicto-posconflicto en Colombia como reconstrucción ética y politica de la sociedad, Antropos, Bogotá.

Beristain, Carlos

1999 Reconstruir el tejido social, Icaria, Barcelona, $287 \mathrm{pp}$.

Castillo, Jesús

20II Migraciones ambientales. Huyendo de la crisis ecológica en el siglo xxI, Virus editorial, Barcelona, II2 pp.

Centro Memoria Histórica

2012 Justicia y paz: ¿verdad judicial o verdad histórica?, Taurus Pensamiento, Bogotá, 615 pp.

Cernea, Michael

I997 "The Risks and Reconstruction Model for Resettling Displaced Populations", en World Development, núm. IO, pp. 1569-1587. 
Chihu, Aquiles y Alejandro López

2004 "El análisis de los marcos en la obra de William Gamson", en Estudios

Sociológicos, vol. xxII, núm. 2, mayo-agosto, pp. 435-460.

CNRR, Grupo Memoria Histórica

2009 Memorias en tiempo de guerra. Repertorio de iniciativas, Punto aparte, Bogotá, $250 \mathrm{pp}$.

CNRR, Grupo Memoria Histórica, IEPRI

2009 El Despojo de Tierras y Territorios. Aproximación conceptual, Bogotá, $250 \mathrm{pp}$.

CODHES

2013 "La crisis humanitaria en Colombia persiste. El Pacífico en disputa. Informe de desplazamiento forzado en 2012", en Documentos Codhes, núm. 26, 93 pp.

Coronado, Sergio

2010 Tierra, autonomía y dignidad. Conflictos territoriales de los pueblos indi-

Delgado, Manuel genas de la Sierra Nevada de Santa Marta, Cinep, Bogotá, I30 pp.

1999 Ciudad líquida, ciudad interrumpida, Universidad de Antioquia, Medellín, $192 \mathrm{pp}$.

Elias, Norbert y John Scotson

1997 Logiques de l'exclusion, Fayard, París, 279 pp.

Ferro, Juan Guillermo, Flor Edilma Osorio, Graciela Uribe y Olga Lucía Castillo 1999 Jóvenes, coca y amapola. Un estudio de las transformaciones socioculturales en zonas de cultivos ilícitos, Pontificia Universidad Javeriana, Bogotá, $175 \mathrm{pp}$.

Fierro, Julio

201 Políticas mineras en Colombia, Ilsa, Bogotá, 259 pp.

Foucault, Michel

2000 Defender la sociedad. Curso en el Collège de France (1975-1976), Fondo de

Cultura Económica, Buenos Aires, 287 pp.

Fraser, Nancy

2008 Escalas de justicia, Herder, Barcelona, 294 pp.

Fundación Esperanza

201 "Migración y tráfico humano. Diálogos migrantes", en Revista del Observatorio de Migraciones, núm. 6, pp I02. 
Galtung, Johan

1998 Tras la violencia 3 R: reconstrucción, reconciliación y resolución. Afrontando los efectos visibles e invisibles de la guerra y la violencia, Bakeaz e Gernika Gogoratuz, Bilbao, 123 pp.

Garay, Jorge Luis y Fernando Barbieri

2012 "Usurpación y abandono de tierras y demás bienes de la población desplazada, Justicia distributiva en sociedades en transición”, en Morten Bergsmo, César Rodríguez Garavito, Pablo Kalmanovitz, María Paula Saffon (eds.), Justicia distributiva en sociedades en transición, Torkel Opsahl Academic EPublisher, Oslo, 468 pp.

García, Antonio

1973 Sociología de la reforma agraria en América Latina, Cruz del Sur, Bogotá, $238 \mathrm{pp}$.

García, Clara Inés

1996 Urabá. Región, actores y conflicto 1960-1990. Iner, Cerec, Santafé de Bogotá, 288 pp.

García, Mauricio

2003 "Apuntes sobre codificación y costumbre en la historia del derecho colombiano" en Opinión Jurídica, núm. 8, julio-diciembre, pp 53-7I.

Grupo Memoria Histórica, GMH

2013 ¡Basta ya! Colombia: Memorias de guerra y dignidad, Imprenta Nacional, Bogotá, 433 pp.

201 La buella invisible de la guerra. Desplazamiento forzado en la comuna 13 de Medellín, Taurus Pensamiento, Bogotá, 332 pp.

Harvey, David

2004 "El 'nuevo' imperialismo: Acumulación por desposesión", en Socialist Register. El Nuevo desafío imperial <http://bibliotecavirtual.clacso. org.ar/ar/libros/social/harvey.pdf > [agosto de 2013]

Ibáñez, Ana María

2008 El desplazamiento forzoso en Colombia: un camino sin retorno a la pobreza, Universidad de los Andes, CEDE, Bogotá, 277 pp.

Ibáñez, Ana María y Juan Carlos Muñoz

2012 "La persistencia de la concentración de la tierra en Colombia: ¿qué pasó entre 2000 y 2009 ?", en Morten Bergsmo, César Rodríguez, Pablo Kalmanovitz y María Paula Saffon (eds.), Justicia distributiva en sociedades en transición, Torkel Opsahl Academic EPublisher, Oslo, 468 pp. 
IDMC

201 "México. Desplazamiento debido a violencia criminal y comunal", Internal displacement Monitoring Centre Norwegian Refugee Council. $<$ http://www.acnur.org/t3/uploads/pics/Mexico___Desplazamiento_ debido_a_violencia_criminal_y_comunal_-_IDMC_20II.pdf?view=I > [julio de 20I3]

Jaramillo, Ana María

2010 La fuerza de la razón sobre las armas. Resistencia civil no violenta y participación ciudadana en el Oriente Antioqueño, Colombia: 2001-2004, Clacso, Buenos Aires, iIo pp.

Jaramillo, Jaime Eduardo, Leónidas Mora y Fernando Cubides

1989 Colonización, coca y guerrilla. Presencia, 322 pp.

Job, Vanessa

201 "700 mil desplazados. Nos tuvimos que ir", en emeequis < http // Www.m-X+com.mx/20II-08-2I/nos-tuvimos-que-ir $>$ [julio de 20I3].

Kalivas, Stathis

2004 "La ontología de la violencia política' acción e identidad en las guerras civiles", en Análisis Político, núm 52, septiembre-diciembre, pp 5075.

Lang, Miriam

201 "Crisis civilizatoria y desafíos para las izquierdas", en Miriam Lang y Dunia Mokrani (comps.), Más allá del desarrollo. Grupo permanente de trabajo sobre Alternativas al desarrollo, Fundación Rosa Luxemburgo Abya Yala, Quito.

Lara, Claudio

2012 "Prólogo", en Julio C. Postigo (ed.), Cambio climático, movimientos sociales y politicas públicas. Una vinculación necesaria, clacso, Santiago de Chile.

Lewkowicz, Ignacio

2004 Pensar sin Estado. La subjetividad en la era de la fluidez, Paidós, Buenos Aires, $252 \mathrm{pp}$.

López, Claudia (ed.)

$2010 Y$ refundaron la patria... De cómo mafiosos y politicos reconfiguraron el Estado Colombiano, Nuevo Arco Iris, Congreso Visible, Grupo Método y moe, Bogotá: Debate, 78 pp.

Lozano, Fabio

2003 "Desarraigos e imaginarios religiosos. Apuntes para un horizonte de comprensión”, en Conflictos, regiones e imaginarios religiosos. Un estudio 
con énfasis en los imaginarios de la población en situación de desplazamiento en Chocó, Caquetá, Magdalena Medio y Bogotá. Informe de investigación. Universidad Javeriana, Colciencias, Bogotá.

Maffesoli, Michel 1997 Du nomadisme, Biblio essais. Le livre de poche, París, I50 pp.

Mate Rupérez, Manuel 2005 A contraluz, Anthropos, Barcelona, $190 \mathrm{pp}$. Melguizo, María Clara

2003 Trapitos al sol: Relatos sobre niñas y niños trabajadores domésticos en Colombia, Organización Internacional del Trabajo, Bogotá, 55 pp.

Molano, Alfredo

1987 Aguas arriba, El Ancora Editores, Bogotá 177 pp.

1987 Selva adentro, El Ancora Editores, Bogotá, I38 pp.

I989 Siguiendo el corte, El Ancora Editores, Bogotá, 321 pp.

Moncada, Juan José

20II Realidades del despojo de tierras. Retos para la paz en Colombia, IPC, Medellín, 358 pp.

Morin, Edgar

1995 Sociología, Tecnos, Madrid, 4Io pp.

ONU

2013 "Las grandes consecuencias del cambio climático, los comentarios del Secretario General ante el Consejo de Relaciones Exteriores" < http:// www.un.org/es/climatechange/newsi2feb2or3.shtml> [agosto de 2013]

Osorio, Flor Edilma y Mauricio Herrera

2012 "Prácticas de seducción y violencia hacia la quimera del progreso: la combinación de las formas de lucha del capital”, en Autonomías territoriales: Experiencias y desafios. Observatorio de Territorios Étnicos, Pontificia Universidad Javeriana, Bogotá, pp. 297-325.

Osorio, Flor Edilma, William Mejía y Gloria Restrepo

2010 "Ausencias presentes para construir futuros. Impactos de la migración internacional en la dinámica familiar en el municipio colombiano de Córdoba, Quindío", en Laredvista, núm. I, junio-diciembre, pp. 263-279.

Parsons, James

1997 La colonización antioqueña en el occidente de Colombia, El Ancora, Bogotá, $302 \mathrm{pp}$. 
Piña, Efrén

2012 Entre la frontera del desarrollo y el desarrollo de la frontera, Odecofi, Cinep, Bogotá, 286 pp.

Posso, Jeanny

2008 La inserción laboral de las mujeres inmigrantes negras en el servicio doméstico de la ciudad de Cali, Universidad del Valle, Cali, 397 pp.

Ramírez, María Clemencia

2001 Entre el estado y la guerrilla: identidad y ciudadanía entre los movimientos de los campesinos cocaleros del Putumayo, ICANH, Bogotá, 35I pp.

Richmond, Anthony

1993 "Reactive Migration: Sociological Perspectives on Refugee Movements", en Journal of Refugee Studies, núm. 6, pp 7-24.

Rodríguez, Cesar y Natalia Orduz

2012 Adiós río. La disputa por la tierra, el agua y los derechos indígenas en torno a la represa de Urrá, Centro de Estudios de Derecho, Justicia y Sociedad, Dejusticia, Bogotá, 188 pp.

Romero, Mauricio (ed.)

20II La economía de los paramilitares, Corporación Nuevo Arco Iris y Random House Mondadori, Bogotá, 524 pp.

Roniger Luis

201 "Destierro y exilio en América Latina: un campo de estudio transnacional e histórico en expansión", en Pacarina del Sur. Revista de pensamiento crítico latinoamericano, dossier I, octubre-diciembre. <http://www. pacarinadelsur.com/home/abordajes-y-contiendas/318-destierro-y-exilio-en-america-latina-un-campo-de-estudio-transnacional-e-historico-en-expansion $>$ [febrero de 20I4].

Simmel, George

I979 “Digressions sur l'étranger", en Y. Grafmeyer e I. Joseph, L'Ecole de Chicago, Editions du Champ Urbain, París.

Svampa, Maristella

2012 "Consenso de los commodities, giro ecoterritorial y pensamiento crítico en América Latina", en Revista Observatorio Social para América Latina OSAL, núm. 32, septiembre, pp 15-38.

Tobasura, Isaías

2004 Boyacenses en Caldas: una colonización silenciosa, Universidad de Caldas, Caldas, $74 \mathrm{pp}$. 


\section{Tobón, Gabriel y Gloria Restrepo}

2009 "Erradicación de cultivos ilícitos y desplazamiento forzado en el parque natural Sierra de la Macarena”, en Cuadernos de Desarrollo Rural, núm. 63, julio-diciembre, pp. I07-I36.

Universidad Nacional, unODC

2009 "Estudio nacional exploratorio descriptivo sobre el fenómeno de trata de personas en Colombia" <www.unodc.org/documents/frontpage/ Investigacion_Trata_co1.pdf $>$ [agosto de 20I3]

Uribe, Graciela

1993 Veníamos con una manotada de ambiciones: Un aporte a la bistoria de la colonización del Caquetá, Bogotá: Presencia, 238 pp.

Vidal, Roberto

2007 Derecho global y desplazamiento interno, creación, uso y desaparición del desplazamiento forzado por la violencia en el derecho contemporáneo, Universidad Javeriana, Bogotá, 272 pp.

Yory, Carlos Mario

1999 Topofilia o la dimensión poética del habitar, Centro Editorial Javeriano, CEJA, Bogotá, $387 \mathrm{pp}$. 